\title{
Retraction Note: A Hot Pepper cDNA Encoding a Pathogenesis-Related Protein 4 Is Induced during the Resistance Response to Tobacco Mosaic Virus
}

\author{
Chang-Jin Park, Ryoung Shin, Jeong Mee Park, Gil-je Lee, Tae Hyoung Yoo, and Kyung-Hee Paek*
}

Retraction Note: Mol. Cells 11 (2001) 122-127

\begin{abstract}
Members of the editorial board have unanimously agreed to retract the article [Mol. Cells 11 (2001) 122-127] for potential misconducts mainly concerning manipulation and repeated uses of photomicrographs of control data internally along with mislabeling and/or externally in multiple publications. As specified in the "Instructions to Authors", Molecules and Cells (Mol. Cells) explicitly prohibits mis-representation or falsification of experimental data including duplication of previously published data. In the article, lanes 1-6 and lanes 9-11 of rRNA gel in Fig. $3 \mathrm{~A}$ are identical to lanes $1-6$ and lanes 7-9 in Fig. 3C, respectively; two EtBr gels of rRNA in Fig. 4A are identical, and lanes 1-6 and lanes 10-15 in the EtBr gel of rRNA in Fig. 4B are mirror images of each other.
\end{abstract}

